\title{
UKURAN LAYAK TANGKAP IKAN PELAGIS KECIL DI PERAIRAN KENDARI, SULAWESI TENGGARA
}

\author{
Decent Size Capture of Small Pelagics in Kendari Waters, Southeast Sulawesi
}

Oleh:

Heri Widiyastuti ${ }^{1}$, Herlisman ${ }^{2}$, Andina Ramadhani Putri Pane ${ }^{3}$

\footnotetext{
${ }^{1}$ Balai Riset Perikanan Laut, Komp. Raiser Ikan Hias Jl. Raya Bogor Km. 47 Nanggewer Mekar Cibinong Bogor. heriwidiyastuti@gmail.com

2 Balai Riset Perikanan Laut, Komp. Raiser Ikan Hias Jl. Raya Bogor Km. 47 Nanggewer Mekar Cibinong Bogor. yellherlisman@gmail.com

${ }^{3}$ Balai Riset Perikanan Laut, Komp. Raiser Ikan Hias Jl. Raya Bogor Km. 47 Nanggewer Mekar Cibinong Bogor. andina1984@gmail.com
}

* Korespondensi: heriwidiyastuti@gmail.com

\begin{abstract}
The small pelagic resources in the waters of Kendari (FMA 714) that are dominant are mackerel scad (Decapterus macarellus) and Indian mackerel (Rastrelliger kanagurta). Fishing in these waters uses a mini purse seine, with the production of 2 species of fish has reached $38.2 \%$ of the total allowed catch FMA 714. Because of intensive use, management needed to preserve resources. The purpose of this study is to determine the decent size based on a comparison of length of the first capture $(L C)$ and the length of first mature $(L m)$, and prediction of spawning season. Data collection was conducted by researchers and assisted by enumerators monthly. The results showed that the size of the mackerel scad in between $17.5-30.5 \mathrm{~cm} \mathrm{FL} \mathrm{(} n=3207$ tails). The size of the Indian mackerel found between $18.5-26.5 \mathrm{~cm} \mathrm{FL}(n=2556)$. The length at first captured of both species was larger than the size at first matured $(L m>L c)$ so that the decent size is $23 \mathrm{~cm} F L$ for mackerel scad and $22 \mathrm{~cm}$ FL for Indian mackerel. The prediction of the spawning season in MayAugust can be the basis for closing the area during the spawning season.
\end{abstract}

Keywords: : mackerel scad, Indian mackerel, mini purse seine, decent size, FMA 714

\section{ABSTRAK}

Sumberdaya pelagis kecil di perairan Kendari (WPP 714) yang dominan adalah ikan layang biru (Decapterus macarellus) dan ikan banyar (Rastrelliger kanagurta). Penangkapan ikan di perairan ini menggunakan mini purse seine dan produksi 2 jenis ikan ini sudah mencapai 38,2\% dari total JTB WPP 714. Oleh karena pemanfaatan yang intensif maka diperlukan pengelolaan untuk menjaga kelestarian sumberday. Tujuan dari penelitian ini adalah menentukan ukuran layak tangkap berdasarkan perbandingan ukuran rata-rata tertangkap (LC) dan ukuran ikan rata-rata matang gonad (Lm) dan prediksi musim pemijahan. Pengumpulan data dilakukan peneliti dan dibantu oleh enumerator secara bulanan. Hasil kajian menunjukkan bahwa sebaran ikan layang biru pada ukuran $17,5-30,5 \mathrm{cmFL}(\mathrm{n}=3207$ ekor). Ikan banyar ditemukan pada kisaran panjang 18,5 - 26,5 cmFL ( $\mathrm{n}$ $=2556$ ). Ukuran rata-rata tertangkap kedua spesies masih lebih besar dibanding ukuran pertama kali matang gonad ( $\mathrm{Lm}>\mathrm{Lc}$ ), sehingga ukuran layak tangkap bagi ikan layang biru yaitu $23 \mathrm{cmFL}$ (layang biru) dan $22 \mathrm{cmFL}$ (banyar). Prediksi musim pemijahan terjadi pada Mei - Agustus dapat menjadi dasar dalam penutupan area saat musim pemijahan.

Kata kunci: Ikan layang biru, ikan banyar, mini purse seine, ukuran layak tangkap, WPP 714 


\section{PENDAHULUAN}

Perairan Indonesia mempunyai potensi ikan pelagis tersebar di seluruh pesisir karena kesuburan perairan yang menjadi daerah penangkapan ikan potensial. Salah satu wilayah yang menghasilkan ikan pelagis kecil adalah perairan Kendari yang masuk ke bagian Laut Banda (Hariati 2011). Perairan Kendari ini merupakan bagian dari Wilayah Pengelolaan Perikanan (WPP) 714. Perairan ini mempunyai banyak pulau-pulau yang relatif dangkal yang disukai ikan pelagis kecil karena biasanya habitatnya di kedalaman 0-200 m (Nusir 2012).

Perikanan pelagis kecil dominan dilakukan oleh perikanan skala kecil dengan alat tangkap beragam. Alat tangkap yang biasa digunakan adalah purse seine, payang, bagan, jaring insang, jaring tepi, pancing dan lampara (Genisa 1998). Perikanan pelagis kecil di Kendari dominan tertangkap dengan purse seine atau biasa disebut mini purse seine/jaring gae. Berdasarkan data Pelabuhan Perikanan Samudera Kendari bahwa pada tahun 2017 ada sekitar $83 \%$ dari total produksi hasil tangkapan (25.442 ton) yang berasal dari WPP 714 dan 81\% (17.095 ton) merupakan hasil tangkapan purse seine. Hariati (2011) menyebutkan hasil tangkapan mini purse seine Kendari didominasi oleh ikan layang (Decapterus macrosoma dan Decapterus macarellus) dan tongkol (Auxis spp. dan Euthynnus spp.). Ikan pelagis lainnya yaitu banyar (Rastrelliger kanagurta), siro (Ambligaster sirm), tembang (Sardinella gibbosa), dan selar (Selar crumenophthalmus dan Selaroides leptolepis), cakalang (Katsowonus pelamis) dan tuna (Thunnus spp.).

Ikan pelagis kecil merupakan ikan ekonomis yang banyak dikonsumsi oleh masyarakat karena kandungan proteinnya yang tinggi. Salah satu jenis ikan pelagis adalah ikan kembung yang kandungan proteinnya mencapai 17 $20,83 \%$ dengan kadar lemak sekitar 0,37-3,32\% (LabKes Makassar (2016) dalam Damayati et al. 2017). Tingginya permintaan akan memacu peningkatan penangkapan untuk memenuhi pasar. Produksi 2 komoditas utama ikan pelagis kecil di Sulawesi Tenggara tahun 2017 adalah layang $35.317 .584 \mathrm{~kg}$ dan kembung 15.396.179 kg (Satu Data Kelautan dan Perikanan, 2018). Walaupun produksi 2 komoditas pelagis kecil ini masih 38,2\% dari total jumlah total tangkapan yang diperbolehkan di WPP 714 (PERMEN KP Nomor 50 tahun 2017), namun tetap harus dilakukan pengelolaan untuk menjaga kelestarian populasinya.

Pengelolaan perikanan dapat ditentukan dengan kajian ilmiah berdasarkan status stok dan memerlukan data dan aspek biologi (Zamroni \& Suwarso 2011). Salah satu data biologi yang mudah diperoleh adalah data ukuran panjang yang kemudian dapat diolah menjadi informasi penting dalam dasar penentuan strategi pengelolaan perikanan. Boer (1996) menyatakan bahwa histogram frekuensi panjang ikan adalah teknik yang paling sederhana yang mudah penerapannya untuk mengetahui tingkatan stok ikan. Widiyastuti et al. (2016) juga menambahkan bahwa indikasi kondisi stok ikan yang mengalami gangguan salah satunya adalah adanya perubahan ukuran panjang ikan dari tahun ke tahun. Bahkan Pamenan et al. (2016) juga menyatakan bahwa ukuran frekuensi panjang ikan dapat menjadi dasar dalam kajian selektivitas alat tangkap seperti purse seine. Informasi penting dari aspek biologi lainnya adalah ukuran pertama kali matang gonad dan musim pemijahan. Kedua informasi ini dapat diperoleh dari hasil analisa terhadap tingkat kematangan gonad ikan. Sebagaimana disampaikan Zamroni \& Suwarso (2011) bahwa ukuran pertama kali matang gonad perlu diketahui agar ukuran suatu alat tangkap dapat dirancang dalam memanfaatkan suatu sumber daya ikan,

Oleh karena itu penelitian ini perlu dilakukan untuk mengetahui ukuran layak tangkap berdasarkan perbandingan ukuran pertama kali matang gonad dan ukuran pertama kali matang gonad. Selain itu tujuan dari penelitian ini adalah untuk mengetahui musim pemijahan ikan pelagis kecil di Perairan Kendari. Diharapkan dengan diperolehnya ukuran layak tangkap dan musim pemijahan ikan pelagis kecil, dapat dijadikan informasi dasar dalam penyusunan manajemen pengelolaan perikanan pelagis kecil di Perairan Kendari.

\section{METODE}

\section{Pengumpulan Data}

Lokasi penelitian dilakukan di Pangkalan Pendaratan Ikan (PPI) Sodohoa, Kendari. Pengumpulan data dilakukan oleh peneliti dan dibantu oleh enumerator sejak bulan AprilDesember 2018. Enumerator yang dipilih telah mendapatkan pelatihan khusus dari Balai Riset Perikanan Laut, KKP serta di fasilitasi buku pedoman sampling dan pengamatan jenis kelamin dan tingkat kematangan gonad ikan.

Jenis ikan sampel yang diambil adalah ikan layang biru (Decapterus macarellus) dan ikan banyar (Rastrelliger kanagurta) seperti pada Gambar 1. Kapal mini purse seine yang disampling adalah kapal yang memiliki daerah penangkapan mini purse seine di sekitar 
Perairan Sulawesi Tenggara dan berbasis mendaratkan hasil tangkapannya di PPI Sodohoa, Kendari (Gambar 2). Pengambilan sampel ikan dilakukan secara acak dari kapalkapal mini purse seine tersebut. Hasil tangkapan umumnya sudah disortir di tengah laut sehingga pengambilan ikan contoh diambil dari 1 keranjang sampel. Bila suatu species ikan contoh jumlahnya lebih dari 75 ekor maka diukur 75 ekor saja; sedangkan bila jumlahnya kurang dari 75 ekor maka diukur semua.

Pengukuran panjang cagak ikan layang biru dan banyar dilakukan menggunakan penggaris ataupun kertas ukur yang telah distandarkan oleh Balai Riset Perikanan Laut, KKP. Kegiatan pembedahan dilakukan oleh peneliti dan enumerator untuk mengetahui tingkat kematangan dan berat gonad. Peralatan bedah yang digunakan gunting dan pinset. Berat gonad ditimbang dengan menggunakan timbangan gonad skala 0,01 gram. Total jumlah sampel ikan layang biru yang diukur sebanyak 3.207 ekor dan 772 ekor diantaranya dilakukan pembedahan. Ikan banyar memiliki total sampel sebanyak 2.556 ekor dengan 485 ekor dilakukan pembedahan.

\section{Analisis Data}

Data yang diperoleh oleh peneliti dan enumerator selanjutnya dianalisa untuk mengetahui frekuensi ukuran ikan yang tertangkap. Tingkat kematangan gonad Holden \& Raitt (1974) dalam Zamroni, A \& Suwarso (2011) pada Tabel 1.

Selanjutnya frekuensi ukuran ikan tersebut menjadi dasar dalam menghitung ratarata ukuran panjang tertangkap (LC50\%). Ratarata ukuran panjang pertama tertangkap (Lc/length at first capture) diperoleh dengan pendekatan fungsi logistik yang berbasis data panjang cagak ikan mengikuti persamaan (Jones 1976 dalam Sparre dan Venema 1999) :

$S_{L} e s t=\frac{1}{1+e^{\left(S_{1}-S_{2} L\right)}}$

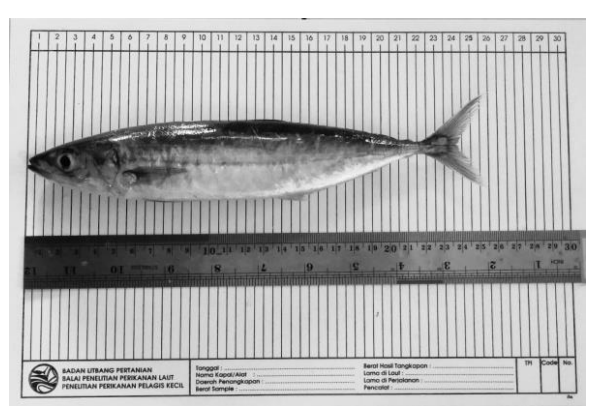

(a)

$$
\begin{aligned}
& \operatorname{Ln}\left[\frac{1}{S_{L}}-1\right]=S_{1}-S_{2} L \\
& L_{50 \%}=\frac{S_{1}}{S_{2}} \text {. } \\
& S L \quad=\text { kurva logistik; } S_{1}=\mathrm{a} ; \mathrm{S}_{2}=\mathrm{b} \\
& \mathrm{S}_{1} \text { dan } \mathrm{S}_{2}=\text { konstanta pada rumus kurva } \\
& \text { logistik. }
\end{aligned}
$$

Selanjutnya rata-rata ukuran pertama kali matang gonad (Lm) dianalisa dengan menggunakan Spearmean-Karber seperti yang diusulkan Udupa (1986) sebagai berikut :

$m=x k+\left(\frac{X}{2}\right)-\left(X \sum p i\right)$

dengan :

$\mathrm{m}=$ log panjang ikan pada kematangan gonad penama

$\mathrm{Xk}=$ log nilai tengah kelas panjang dimana semua ikan (100\%) sudah matang gonad

pi = proporsi ikan matang pada kelas ke-i dimana $\mathrm{pi}=\mathrm{ri} / \mathrm{ni}$ apabila $\mathrm{ni}=\mathrm{ni}+\mathrm{l}$

ri = jumlah ikan matang pada kelas panjang ke-i maka panjang ikan pada waktu mencapai kematangan yang pertama (M) adalah $\mathrm{M}=\operatorname{antilog}(\mathrm{m})$.

Jika tingkat kepercayaan 95\% $(a=0,05)$ dari $(\mathrm{m})$ digunakan, maka kisarannya adalah antilog $\left[m \pm 1,96 \sqrt{ }\left(x^{2} \sum\left(p_{i}{ }^{*} q_{i} / n_{i}-1\right)\right)\right]$. Perbandingan ukuran rata-rata tertangkap (Lc) dengan ukuran pertama kali matang gonad (Lm) akan dianalisa untuk mengetahui ukuran layak tangkap ikan.

Selanjutnya analisa indeks kematangan gonad (Gonado Somatic Indeks/GSI) yang digunakan sebagai parameter pemijahan ikan, perhitungannya menggunakan persamaan menurut Johnson (1971) dalam Effendie (1997) yaitu:

$\mathrm{GSI}=\frac{\mathrm{Wg}}{\mathrm{BW}} \times 100 \%$

dengan:

$\mathrm{Wg}=$ bobot gonad (ovary/testis segar)

BW = bobot tubuh ikan

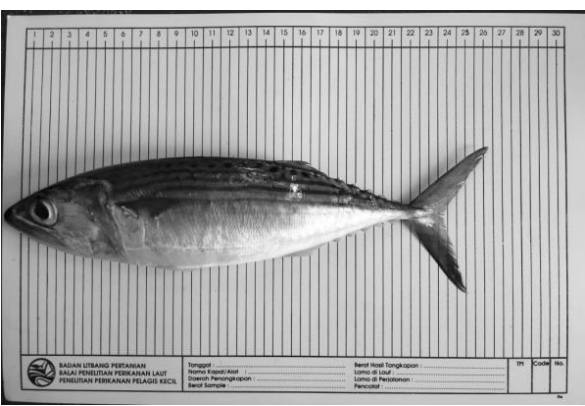

(b)

Gambar 1 Jenis ikan sampling yaitu ikan layang biru (a) dan ikan banyar (b) 


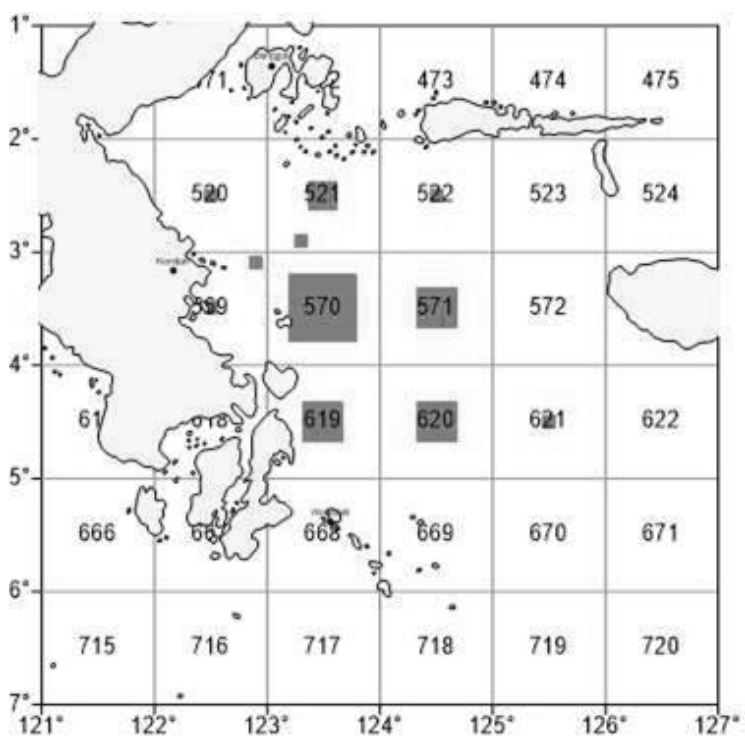

Gambar 2 Daerah penangkapan mini purse seine yang mendaratkan di Kendari, Sulawesi Tenggara

Tabel 1 Deskripsi Tingkat Kematangan Gonad

\begin{tabular}{|c|c|c|}
\hline $\begin{array}{l}\text { Tingkat } \\
\text { Kematangan } \\
\text { Gonad }\end{array}$ & Status & Deskripsi \\
\hline I & Dara / Immature & $\begin{array}{l}\text { Ovary dan testis kecil padat, menempel dekat } \\
\text { lubang anus, dan bentuk silindris, ovary berwarna } \\
\text { kemerahan jernih, translucent; testis keputihan. } \\
\text { Sering kali tertutup lemak. GSI : 0,11-2,69 }\end{array}$ \\
\hline II & $\begin{array}{c}\text { Perkembangan / } \\
\text { Maturing }\end{array}$ & $\begin{array}{l}\text { Ovary dan testis ukuran sampai } 1 / 2 \text { panjang } \\
\text { rongga badan. Ovary kemerahan jernih, testis } \\
\text { putih kira-kira simetris. Butiran ova tidak Nampak } \\
\text { oleh mata telanjang. GSI : } 0,28-4,75\end{array}$ \\
\hline III & $\begin{array}{c}\text { Pematangan / } \\
\text { Ripening }\end{array}$ & $\begin{array}{l}\text { Ovary dan testis ukuran } 1 / 2-2 / 3 \text { panjang rongga } \\
\text { badan. Ovary berwarna kening-kemerahan, } \\
\text { terlihat jelas butiran-butiran telurnya; Nampak } \\
\text { pembuluh darah pada permukaannya; testis } \\
\text { berwarna putih. Tidak ada telur } \\
\text { transparan/translucent. GSI : 0,59-7,19 }\end{array}$ \\
\hline IV & Matang / Mature - ripe & $\begin{array}{l}\text { Ovary dan testis ukuran } 2 / 3 \text { sampai memenuhi } \\
\text { rongga badan. Ovary berwarna orange-pink } \\
\text { dengan banyak pembuluh darah, Transparan, } \\
\text { butiran ova besar, ripe, dan translucent. Testis } \\
\text { putih lembek GSI : } 2,59-11,24\end{array}$ \\
\hline V & Mijah / spent & $\begin{array}{l}\text { Ovarium dan testis berukuran sampai } 1 / 2 \text { dari } \\
\text { panjang rongga badan. Dinding-dindingnya } \\
\text { meluruh. Ovary berisi sisa hancuran buram dan } \\
\text { telur yang matang, gelap, atau transparan. Testis } \\
\text { berwarna merah darah dan lembek. GSI : 0,53- } \\
7,73\end{array}$ \\
\hline
\end{tabular}

\section{HASIL}

\section{Sebaran Ukuran Ikan Pelagis Kecil}

Jumlah sampel ukuran ikan layang biru bervariasi setiap bulannya, jumlah sampel terendah pada bulan November (220 ekor) dan tertinggi pada bulan April (636 ekor). Sebaran ukuran panjang cagak ikan layang biru berkisar pada ukuran tengah panjang 17,5 - 30,5 cmFL (Gambar 2). Modus ukuran ikan layang biru 24,5 cmFL (17,8\%). Kisaran jumlah sampel ikan banyar per bulannya yaitu 176-488 ekor. Sebaran ukuran ikan banyar yang diamati 
berada pada kisaran 18,5 - 26,5 cmFL (Gambar $3)$ dengan modus $22,5 \mathrm{cmFL}(20,7 \%)$.

\section{Ukuran rata-rata tertangkap (Lc50) dan Ukuran pertama kali matang gonad (Lm)}

Ukuran rata-rata tertangkap (Lc50) ikan layang biru adalah 23,22 cmFL dan dan ukuran pertama kali matang gonad (Lm) 22,5 cmFL. Nilai Lc ikan layang biru lebih besar dibandingkan dengan nilai Lm-nya. Begitu pula dengan ikan banyar yang memiliki ukuran ratarata tertangkap (Lc50) 22,32 cmFL dan ukuran pertama kali matang gonad (Lm) 21,79 cmFL (Gambar 4). Perbandingan nilai Lc dan Lm pada di berbagai perairan tersaji pada Tabel 2.

\section{Tingkat kematangan gonad dan indeks kematangan gonad}

Tingkat kematangan gonad (TKG) ikan layang biru teridentifikasi pada level TKG 1, 2, 3 dan 4, sedangkan pada banyar ditemukan hingga TKG 5. TKG 1 dan TKG 2 dikategorikan ikan belum matang gonad, sedangkan TKG 3 dan TKG 4 termasuk ikan sudah matang gonad.

Layang biru banyak ditemukan pada kondisi belum matang gonad pada Juli November. TKG 1 dominan tertangkap pada Juli $(69,4 \%)$ dan TKG 2 pada April (29\%). TKG 3 $(43,6 \%)$ banyak ditemukan pada April dan TKG $4(78 \%)$ banyak ditemukan November. Ikan banyar juga ditemukan dalam kondisi belum matang gonad. TKG 1 (68\%) banyak ditemukan pada Agustus, TKG 2 (42,1\%) pada Mei, TKG 3 (31,6\%) pada Mei, TKG $4(72,2 \%)$ dan TKG 5 $(5,56 \%)$ pada November.

Gambar 6 menunjukkan perkembangan Indeks kematangan gonad/Gonad somatic index (GSI). Nilai IKG ikan layang biru pada penelitian ini berkisar 0-8,83\% dan tertinggi pada bulan Mei dan terendah bulan Juli. Ikan banyar memiliki kisaran nilai IKG 0-6,01\% dan IKG tertinggi bulan Juli dan terendah bulan Agustus.
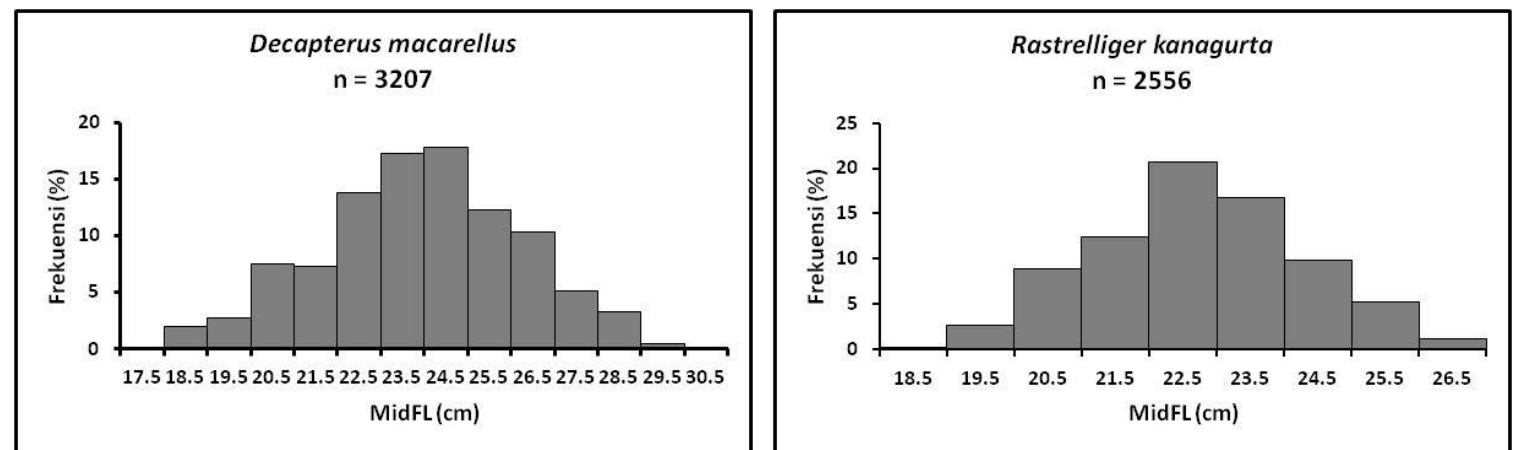

Gambar 3 Sebaran ukuran dan ikan layang biru dan ikan banyar

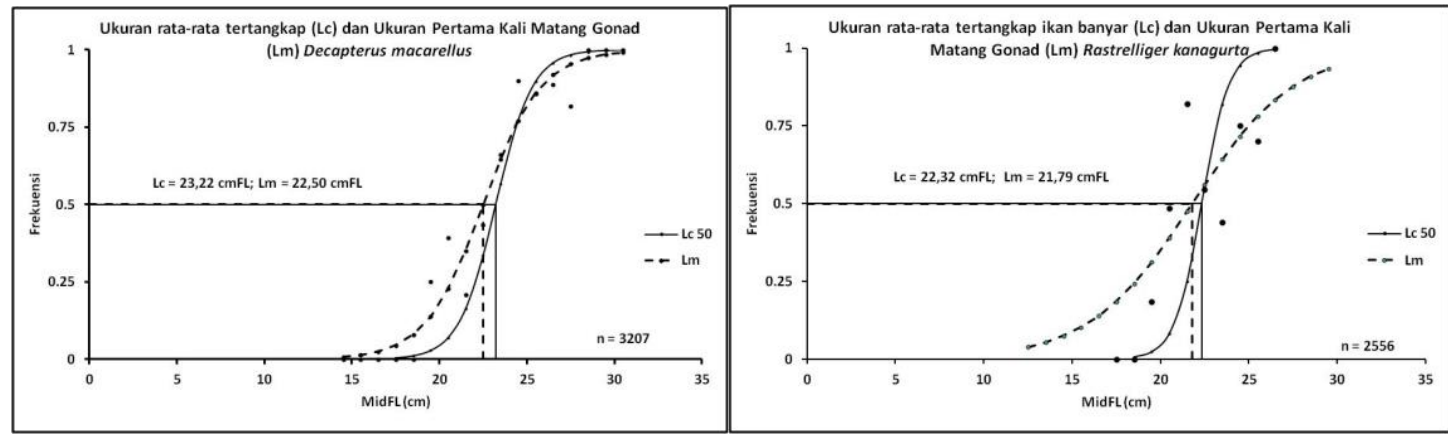

Gambar 4 Ukuran rata-rata tertangkap(LC50) dan ukuran pertama kali matang gonad ikan layang biru dan banyar. 
Tabel 2 Perbandingan ukuran rata-rata ukuran tertangkap (LC) dan ukuran pertama kali matang gonad (Lm) ikan layang biru (Decapterus macarellus) dan ikan banyar (Rastrelliger kanagurta) di berbagai perairan

\begin{tabular}{|c|c|c|c|c|}
\hline No & Lokasi & $\begin{array}{l}\text { Nilai Lc } \\
\text { (cmFL) }\end{array}$ & $\begin{array}{l}\begin{array}{l}\text { Nilai Lm } \\
\text { (cmFL) }\end{array} \\
\end{array}$ & Sumber \\
\hline \multicolumn{5}{|c|}{ Layang Biru (Decapterus macarellus) } \\
\hline 1 & Teluk Tomini & 24,31 & 26,94 & Widiyastuti \& Zamroni, 2017 \\
\hline 2 & Sulawesi Barat & & 18,8 & Nur et al.2017 \\
\hline 3 & Laut Banda & & 26,6 & Zamroni \& Suwarso, 2011 \\
\hline 4 & $\begin{array}{l}\text { Teluk Tomini } \\
\text { dan Laut Maluku }\end{array}$ & 24,6 & 28,87 & Zamroni et al. 2019 \\
\hline 5 & Perairan Kendari & 23,22 & 22,5 & Penelitian ini \\
\hline \multicolumn{5}{|c|}{ Banyar (Rastrelliger kanagurta) } \\
\hline 1 & Selat Malaka & 19,7 & 22,3 & Kuswoyo \& Widiyastuti et al. 2015 \\
\hline 2 & Selat Malaka & & $16,4-17,7$ & Hsb et al. 2015 \\
\hline 3 & $\begin{array}{l}\text { Teluk Tomini } \\
\text { dan Laut Maluku }\end{array}$ & 22,95 & 27,41 & Zamroni et al. 2019 \\
\hline 4 & Mahout & & 25,7 & Zaki et al. 2016 \\
\hline 5 & Perairan Kendari & 22,32 & 21,79 & Penelitian ini \\
\hline
\end{tabular}
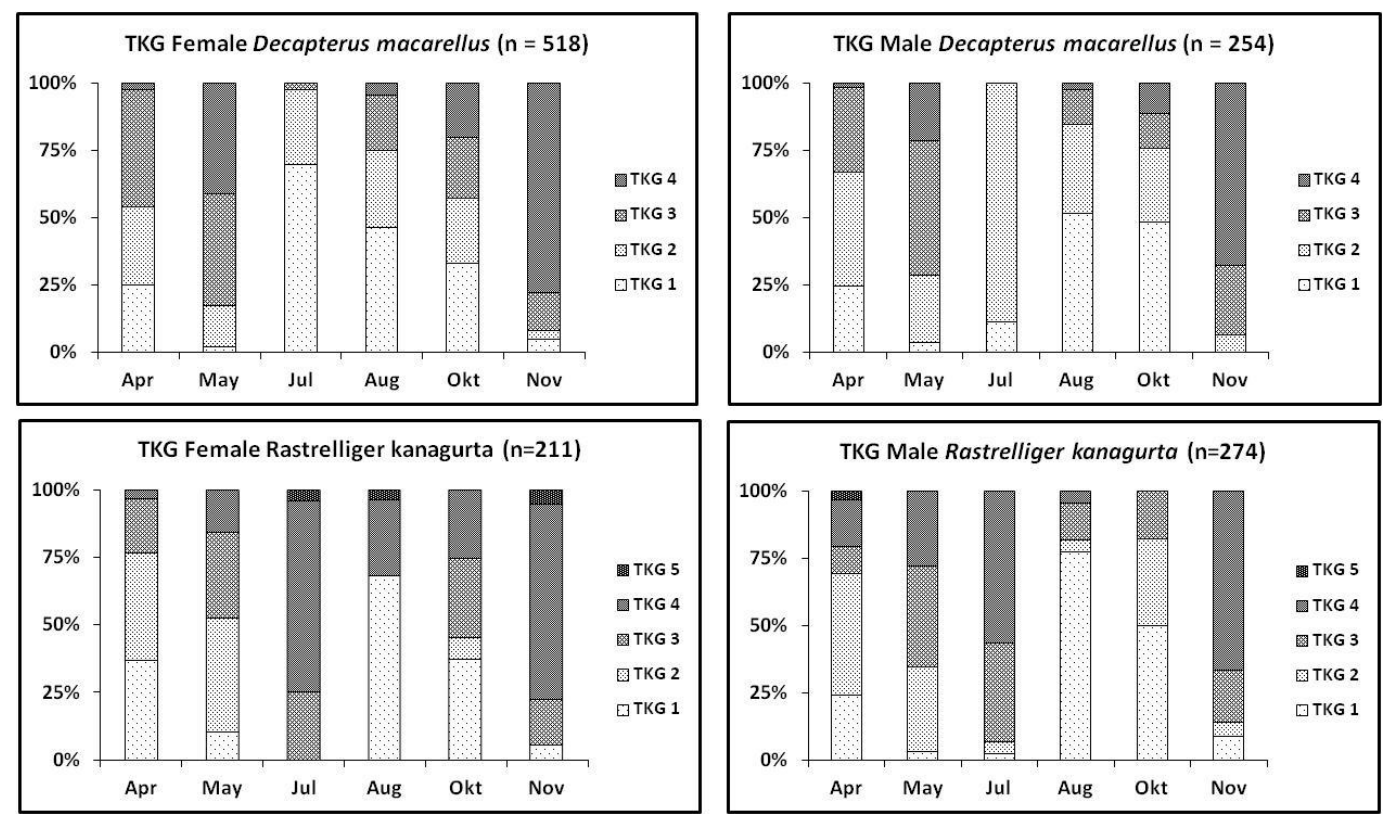

Gambar 5 Tingkat kematangan gonad ikan layang biru dan banyar

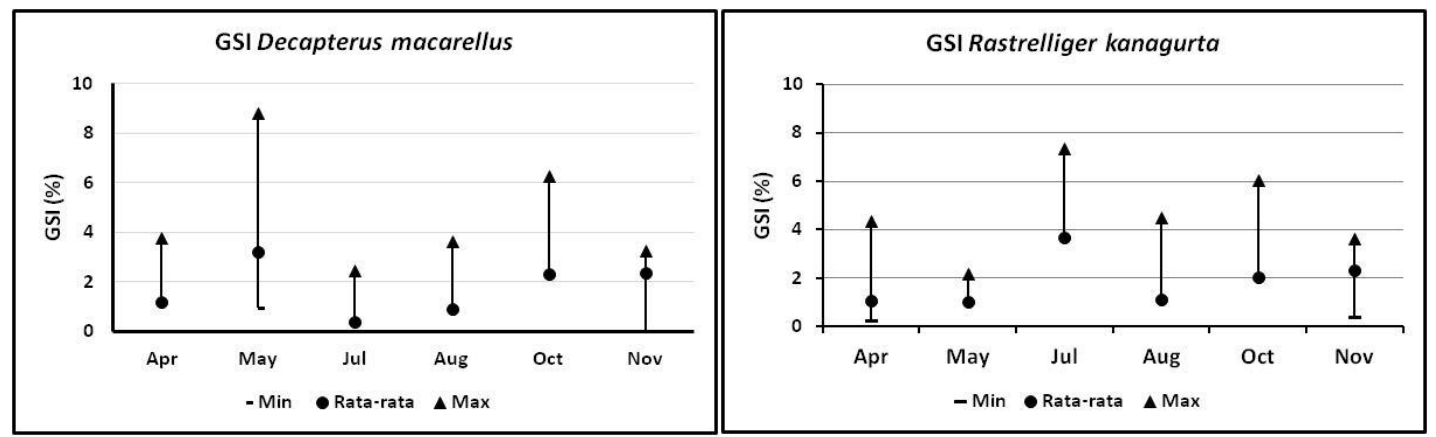

Gambar 6 Indeks kematangan gonad ikan layang biru dan banyar 


\section{PEMBAHASAN}

Sebaran stuktur ukuran ikan menjadi dasar dalam perhitungan ukuran ikan layak tangkap karena ukuran ikan berkaitan dengan kematangan gonad dan ukuran mata jaring yang digunakan. Sebaran ukuran ikan yang dominan tertangkap dalam ukuran kecil dapat menjadi indikator bahwa ikan muda yang tertangkap lebih banyak dibandingkan ikan dewasa sehingga akan mempengaruhi populasi. Maka berdasarkan hasil pengukuran, maka ikan layang biru pada penelitian ini memiliki sebaran ukuran 17,5-30,5 cmFL. Ukuran ini hampir seragam dengan yang ditemukan di Perairan Teluk Tomini dan Laut Maluku 18-32,3 (Zamroni et al. 2019) begitupula dengan hasil penelitian di lokasi yang sama oleh Widiyastuti \& Zamroni (2017), yaitu 17,25 - 30,25 cmFL serta di Perairan Maluku Utara 21,1 - 31,5 cmFL (Iksan \& Irham 2009). Sementara itu, ukuran ikan layang biru yang lebih kecil didapat oleh Zamroni \& Suwarso (2011) di Laut Banda yaitu14,4 - 29,5 cmFL dan di perairan Ambon 11 - 24,5 cmFL (Pattikawa et al. 2018). Menurut Fish Base (2020) bahwa ikan ini maksimal hanya berukuran $46 \mathrm{cmTL}$, walaupun secara umum ditemukan pada ukuran 30 $\mathrm{cm}$.

Sementara hasil ikan banyar mempunyai struktur ukuran $18,5-26,5 \mathrm{cmFL}$ yang lebih besar dibandingkan dengan penelitian sebelumnya 11 - $26 \mathrm{cmFL}$ di Laut Banda (Zamroni \& Suwarso 2011); 14 - 24 cmFL di Perairan Utara Aceh (Hariati \& Fauzi 2011); di Teluk Banten 13,7 - 25,7 cmFL (Safarini \& Mashar 2017); $7,5 \mathrm{~cm}-25,75 \mathrm{~cm} \mathrm{FL} \mathrm{di}$ Perairan Kwandang (Faizah et al. 2017); di Perairan Selat Makassar memiliki sebaran 16$25 \mathrm{~cm}$ untuk rumpon laut dangkal dan 19,520,0 $\mathrm{cm}$ pada rumpon laut dalam (Kantun et al. 2018). Menurut Fish Base (2020) ikan ini masih ditemukan pada ukuran $42.1 \mathrm{cmTL}$ untuk betina namun secara umum pada ukuran $25 \mathrm{cmTL}$ untuk jantan. Ini menunjukkan bahwa ikan diperairan ini masih lebih kecil dibandingkan dengan perairan lain pada umumnya.

Kedua jenis ikan pelagis tersebut ditangkap dengan menggunakan mini purse seine namun terjadi perbedaan sebaran ukuran setiap jenisnya dengan perairan lainnya yang dapat disebabkan oleh ukuran mata jaring dan kedalaman jaring saat dioperasikan. Menurut Fish Base (2020) ikan layang biru biasanya tertangkap pada kedalaman 40-200 m, namun secara umum sebaran ikan pelagis kecil berada kisaran 0 -
50 meter (Suwarso \& Hariati, 2003) sementara mini purse seine Kendari umumnya dioperasikan pada kedalaman lebih dalam yaitu 30-75 m. Hal ini dapat menjadi salah satu indikasi yang menunjukkan ukuran ikan lebih besar berada pada lapisan air lebih dalam. Selain itu Effendie (2002) juga menyebutkan bahwa perbedaan ukuran dipengaruhi oleh makanan, habitat serta sampel yang diukur.

Selanjutnya berdasarkan ukuran ikan yang tertangkap dilakukan analisa pendugaan ukuran ikan pertama kali tertangkap (LC). Ukuran ini identik dengan peluang ikan yang tertangkap (probabilitas) dengan L50\% pada selektivitas alat tangkap tersebut, dimana setiap ukuran ikan yang tertangkap mewakili ikan yang tertangkap atau ikan yang tidak tertangkap di daerah penangkapan. Dasar pengukuran selektivitas ditentukan dengan kisaran panjang terhadap ikan yang di teliti (Sparre\& Vanema 1999). Hubungan ukuran rata-rata tertangkap dan pertama kali matang gonad menjadi acuan untuk mengetahui kondisi ikan yang tertangkap telah mengalami matang gonad atau tidak. Berdasarkan analisa maka diperoleh hasil bahwa ikan pelagis kecil baik ikan layang biru maupun ikan banyar tertangkap setelah mengalami matang gonad $(\mathrm{LC}>\mathrm{Lm})$. Artinya ikan tersebut masih layak tangkap, dan mempunyai kesempatan untuk memijah sebelum tertangkap serta menambah populasi di perairan. Hal tersebut juga dinyatakan oleh Laevastu \& Hayes (1981) bahwa suatu penangkapan dinyatakan layak tangkap apabila telah memberikan peluang bagi ikan untuk bereproduksi sebelum tertangkap.

Namun ukuran rata-rata tertangkap (LC) dan ukuran pertama kali matang gonad (Lm) di berbagai perairan akan mempunyai perbedaan (Tabel 2). Perbedaan tersebut terjadi karena suhu, makanan, sex, hormon dan kondisi perairan (Agustina et al. 2015). Udupa (1986) menyebutkan panjang pertama kali matang gonad tidak harus berasal dari satu kelas umur atau kelas panjang yang sama. Hal ini dikarenakan kondisi lingkungan perairan yang mempengaruhi perbedaan ukuran panjang pertama kali matang gonad.

Tingkat kematangan gonad berkaitan dengan indeks kematangan gonad (IKG) karena bobot gonad semakin bertambah dengan semakin bertambah kematangan gonadnya. Bobot gonad ini juga berbanding lurus dengan bobot tubuh ikan (Zamroni \& Suwarso 2011). IKG ini menjadi dasar dalam penentuan perkiraan musim pemijahan 
(Brewer et al. 2008). Nilai IKG ini juga selaras dengan kematangan gonad, jika IKG tinggi jadi indikasi bahwa ikan sedang full matang gonad sedangkan nilai IKG rendah artinya ikan sudah melakukan pemijahan. Terjadinya penurunan IKG secara signifikan menjadi ciri pemijahan karena bobot gonad menurun dan diduga sebagai musim pemijahan. Musim pemijahan layang biru diduga terjadi pada bulan Mei - Juli dan ini berbeda dengan yang ditemukan oleh Widiyastuti \& Zamroni (2017) di Teluk Tomini pada bulan Agustus dan November. Nur et al. (2017) menyebutkan ikan layang biru di Perairan Sulawesi Barat memijah pada bulan Juni dan di utara Kyusu melakukan pemijahan pada bulan April hingga Juli (Shiraishi et al. 2010).

Prediksi musim pemijahan ikan banyar pada bulan Juli-Agustus yang berbeda dengan di perairan pantai Kuantan pada akhir Januari dan akhir Mei (Rahman \& Hafzath, 2012). Bahkan lebih musim lebih panjang terjadi di pesisir Mahout yang terjadi hampir sepanjang tahun namun utamanya bulan Januari-April dan Agustus-Desember (Zaki et al. 2016). Ikan jenis ini ditemukan Faziah et al. (2017) memijah pada bulan November di perairan Kwandang dan di perairan Madura yaitu bulan Maret-April (Susanti et al. 2019).

Nilai IKG dari 2 jenis ikan pelagis ini kurang dari $20 \%$ menunjukkan bahwa ikan ini adalah ikan yang melakukan pemijahan lebih dari 1 kali (Pulungan et al. (1987) dalam Yustina \& Arnentis (2002). Hal ini yang menjadikan perbedaan puncak musim pemijahan di setiap perairan karena pemijahan ikan layang biru dan banyar terjadi sepanjang tahun. Perbedaan puncak pemijahan di perairan tersebut terjadi karena faktor hormon dan lingkungan habitat hidupnya. Secara umum 2 jenis ikan pelagis kecil di perairan Kendari tersebut melakukan pemijahan antara Mei-Agustus. Prediksi musim pemijahan ini menjadi acuan agar dilakukan kebijakan yang dapat memberikan kesempatan bagi ikan bereproduksi.

Prediksi puncak musim pemijahan yang dilakukan dalam penelitian ini masih kurang dari 1 tahun sehingga diperlukan penelitian lanjutan yang time series. Namun prediksi puncak musim ini tetap dapat dijadikan dasar dalam pengelolaan sehingga Pemerintah dapat mempersiapkan langkahlangkah dalam menjaga kelestarian sumberdaya. Hal tersebut mutlak diperlukan karena memberikan kesempatan bagi sumberdaya pelagis kecil khususnya ikan layang biru dan banyar untuk berkembang biak dan menambah populasi.

Maka secara umum pengelolan sumberdaya ikan layang biru (Decapterus macarellus) ikan banyar (Rastrelliger kanagurta) yang ditangkap dengan mini purse seine di perairan Kendari dapat dilakukan dengan menetapkan kebijakan ukuran layak tangkap dan penutupan area pada waktu musim pemijahan. Kebijakan penetapan ukuran ikan layak tangkap $23 \mathrm{cmFL}$ ikan layang biru dan $22 \mathrm{cmFL}$ ikan banyar harus dilakukan untuk kelestarian sumberdaya. Selain itu penggunaan alat tangkap mini purse seine harus tetap dalam pengawasan karena ukuran mezh size jaring harus sesuai dengan PERMEN KP Nomor 71 Tahun 2016 minimal 1 inch. Kebijakan penutupan area penangkapan saat musim pemijahan Mei-Agustus dapat dilakukan agar ikan dapat melakukan proses recruitmendan menambah populasi. Namun pengelolaan tidak dapat dilakukan hanya oleh pemerintah saja sehingga diperlukan kerjasama dan koordinasi setiap stakeholder yang terlibat dalam pemanfaatan sumberdaya.

\section{KESIMPULAN}

Ukuran rata-rata tertangkap kedua spesies masih lebih besar dibanding ukuran pertama kali matang gonad ( $\mathrm{LC}>\mathrm{Lm})$. Ukuran layak tangkap bagi ikan layang biru sebesar $23 \mathrm{cmFL}$ dan ikan banyar sebesar $22 \mathrm{cmFL}$ agar memberikan kesempatan bagi ikan menambah populasi. Prediksi musim pemijahan Mei - Agustus dapat menjadi dasar dalam penutupan area penangkapan dari penggunaan mini purse seine di perairan Kendari.

\section{SARAN}

Berdasarkan hasil penelitian ini maka dapat dilakukan manajemen kontrol dengan menetapkan peraturan pemerintah daerah tentang ukuran layak tangkap serta penutupan wilayah penangkapan berdasarkan musim pemijahan bagi ikan pelagis kecil.

\section{UCAPAN TERIMA KASIH}

Penelitian ini bagian dari kegiatan Karakteristik Biologi Perikanan serta Habitat Sumber Daya, Potensi Produksi dan Kapasitas Penangkapan di WPP 714 Laut Banda Tahun 2018. Terima kasih kepada Ibu 
Prihatiningsih, M.Si sebagai Penanggungjawab kegiatan dan tim yang telah membantu pengumpulan data di Kendari. Penulis pertama adalah kontributor utama pada karya tulis ini dan penulis kedua dan ketiga sebagai kontributor anggota.

\section{DAFTAR PUSTAKA}

Agustina S, Boer M, Fahrudin A. 2015. Dinamika Populasi Sumber Daya Ikan Layur (Lepturacanthus savala) di Perairan Selat Sunda. Marine Fisheries. 6(1): 77-85.

Boer M. 1996. Pendugaan Koefisien Pertumbuhan $\left(\mathrm{L} \infty, \mathrm{K}\right.$, Dan $\left.\mathrm{t}_{0}\right)$ Berdasarkan Data Frekuensi Panjang. Jurnal IImu-IImu Perairan dan Perikanan Indonesia. 14(1): 75-84.

Brewer SK, Rabeni CF, Papoulias DM. 2008. Comparing Histology and Gonadosomatic Index for Determining Spawning Condition of Small-Bodied Riverine Fishes. Ecol. Freshwater Fish. 17(1): 54-58.

Damayati DS, Jastam MS, Faried NA. 2017. Analisis Kandungan Otak-otak Ikan Kembung (Rastrelliger brachyoma) Subtitusi Buah Lamun (ENhalus acoroides) sebagai Alternatif Perbaikan Gizi di Masyarakat. Al-Sihah : Public Health Science Journal. IX(1): 19-30.

Effendie MI. 1997. Biologi Perikanan. Yogyakarta: Yayasan Pustaka Nusantara.

Effendie HMI. 2002. Biologi Perikanan. Yogyakarta: Yayasan Pustaka Nusantara.

Faizah R, Sadiyah L, Fauzi M. 2017. Population Parameter and Reproductive Biology of Indian Mackerel Rastrelliger kanagurta (Cuvier, 1817) Caught by Lift Net in Kwandang Waters, North Gorontalo. Indonesian Fisheries Research Journal. 23(2): 107-115.

Fish Base. 2020. Decapterus macarellus. http://www.fishbase.us/summary/Speci esSummary.php?ID=993\&genusname $=$ Decapterus $\&$ speciesname $=$ macarellu s\&AT =decapterus+macarellus\&lang $=E$ nglish. Diakses pada 2 Desember 2020
Fish Base. 2020. Rastreliger kanagurta. https://www.fishbase.se/summary/Rast relliger-kanagurta.html. Diakses pada 2 Desember 2020.

Genisa, A. S. 1997. Beberapa Catatan tentang Alat Tangkap Ikan Pelagik Kecil. Oseana. XXIII (3\&4): 19-34.

Hariati T, Fauzi M. 2011. Aspek Reproduksi Ikan Banyar, Rastrelliger kanagurta (Cuvier, 1817) di Perairan Utara Aceh. Jurnal Iktiologi Indonesia. 11(1): 47-53.

Hariati T. 2011. Komposisi Hasil Tangkapan, Musim Penangkapan, dan Indeks Kelimpahan Ikan Pelagis yang Tertangkap Pukat Cincin Mini di Perairan Kendari, Laut Banda. Jurnal Penelitian Perikanan Indonesia. 17(2): 139-146.

Hsb JS, Basyuni M, Suryanti, A. 2015. Hubungan Panjang Bobot dan Reproduksi Ikan Kembung Lelaki Rastrelliger kanagurta (Cuvier, 1817) di Perairan Selat Malaka Tanjung Beringin Serdang Bedagai Sumatera Utara. Aquacoastmarine. 9(4): 89-99.

Iksan KH, Irham. 2009. Pertumbuhan dan Reproduksi Ikan Layang Biru (Decapterus Macarellus) di Perairan Maluku Utara. Jurnal Iktiologi Indonesia. 9(2): 163-174.

Kantun W, Darris L, Arsana WS. 2018. Komposisi Jenis dan Ukuran Ikan yang Ditangkap pada Rumpon dengan Pancing Ulur di Selat Makassar. Marine Fisheries. 9(2): 157-167.

Kuswoyo A, Widiyastuti H. 2015. Status Pemanfaatan Sumber Daya Ikan di Perairan Selat Malaka (WPP-NRI 571). Dalam Ali Suman (Eds.), Keragaan Perikanan Gillnet Ikan Kembung di Selat Malaka (hlm. 121-132). Jakarta : Ref Grafika.

Laevastu T, Hayes ML. 1981. Fisheries Oceanography and Ecology. Fishing News Books. Farnham. 199 hal.

Nur M, Al Ayubi MA, Suprapto, Omar SBA. 2017. Biologi Reproduksi Ikan Layang Biru (Decapterus macarellus Cuvier, 1833) di Perairan Sulawesi Barat. Prosiding Seminar Nasional Kelautan dan Perikanan IV Universitas Hasanudin. pp 201-208. 
Pamenan AR, Sunarto S, Nurruhwati I. 2016. Selektivitas alat tangkap purse seine di Pangkalan Pendaratan Ikan (PPI) Muara Angke Jakarta. Jurnal Perikanan Kelautan. 7(2): 97-102.

Pattikawa JA, Ongkers OTS, Tetelepta JMS, Uneputty PrA, Amirudin A. 2018. Some biological aspects of mackerel scad (Decapterus macarellus) in Ambon Island waters, Indonesia. Internasional Journal of Fisheries and Aquatic Studies. 6(4): 171-175

Rahman MM. Hafzath A. 2012. Condition, Length-Weight Relationship, Sex Ratio and Gonadosomatic Index of Indian Mackerel (Rastrelliger kanagurta) Captured from Kuantan Coastal Water. Journal of Biological Sciences. 12(8): 426-432.

Satu Data Kelautan dan Perikanan. 2018. Satu Data Produksi Kelautan dan Perikanan Tahun 2017. Pusat data Statistik dan Informasi. Kementerian Kelautan dan Perikanan. 322 p.

Safarini D, Mashar A. 2017. Kematangan Gonad dan Potensi Reproduksi Ikan Banyar (Rastrelliger kanagurta, Cuvier 1817). Tropical Fisheries Management Journal. 1(01): 11-16.

Shiraishi T, Tanaka H, Ohshimo S, Ishida H, Morinaga N. 2010. Age, Growth and Reproduction of Two Species of Scad, Decapterus macrosoma and $D$. macarellus in the Waters of Southern Kyushu. Japan Agricultural Research Quarterly: JARQ. 44(2): 197-206.

Sparre P, Venema SC. 1999. Introduksi Pengkajian Stok Ikan Tropis (EdisiTerjemahan). Jakarta (ID): Kerjasama Organisasi Pangan, Perserikatan Bangsa-Bangsa dengan Pusat Penelitian dan Pengembangan Perikanan, Badan Penelitian dan Pengembangan Pertanian. 438 hlm.

Susanti E, Setyanto A, Setyohadi D, Jatmiko I. 2019. Studi Aspek Reproduksi Ikan Kembung Lelaki (Rastrelliger kanagurta, Cuvier 1817) pada Musim
Peralihan di Selat Madura. BAWAL Widya Riset Perikanan Tangkap. 11(1): 45-58.

Tanjov YE, Yusfiandayani R. 2016. Responsible Fisheries Management of Mini Purse Seine in the Lampung Bay Area. Jurnal Ilmu dan Teknologi Kelautan Tropis. 8(2): 713-728.

Udupa, KS. 1986. Statistical Method of Estimating the Size at First Maturity in Fishes. ICLARM. Metro Manila. Fishbyte. 4(2): 8-10.

Widiyastuti H, Zamroni A. 2017. Biologi Reproduksi lkan Malalugis (Decapterus macarellus) di Teluk Tomini. BAWAL Widya Riset Perikanan Tangkap. 9(1): 63-72.

Widiyastuti H, Suprapto, Ali SA. 2016. Beberapa Aspek Biologi Reproduksi Ikan Terbang (Hirundichtys oxycephalus Bleeker, 1852) di Perairan Takalar, Sulawesi Selatan. Prosiding Seminar Nasional Pengelolaan Perikanan Pelagis Universitas Brawijaya, pp 73-76.

Yustina, Arnenti. 2002. Aspek Reproduksi Ikan Kapiek (Puntius schwanefeldi Bleeker) di Sungai Rangau, Riau, Sumatera. Jurnal Matematika dan Sains. 7(1): 5-14.

Zaki S, Jayabalan N, Al-Kiyumi F, Al-Kharusi L. 2016. Reproductive biology of the Indian mackerel Rastrelliger kanagurta (Cuvier, 1816) from the Mahout Coast, Sultanate of Oman. Indian Journal of Fisheries. 63(2): 24-32.

Zamroni A, Widiyastuti H, Kuswoyo A. 2019. Tingkat Kematangan Gonad dan Dugaan Musim Pemijahan Tiga Spesies Ikan Pelagis Kecil yang Didaratkan di Bitung. BAWAL Widya Riset Perikanan Tangkap. 11(2): 113126.

Zamroni A, Suwarso. 2011. Studi tentang Biologi Reproduksi Beberapa Spesies Ikan Pelagis Kecil di Perairan Laut Banda. BAWAL Widya Riset Perikanan Tangkap. 3(5): 337-334. 